\title{
Revista do

\section{O DEBATE DO LÍCITO E DO ILÍCITO NA INTERNET: LIBERDADE DE EXPRESSÃO E REMOÇÃO DE CONTEÚDO}

\author{
Samuel Nunes ${ }^{1}$ \\ Frederico Cardoso de Miranda ${ }^{2}$
}

\begin{abstract}
RESUMO
O presente trabalho buscou uma análise da liberdade de expressão na internet, com base em levantamento das técnicas usadas pelos magistrados para dirimir conflitos nos quais é requerida a remoção de conteúdo da internet, além do exame da eficácia das determinações judiciais e da responsabilização dos provedores. Considerando a estrutura técnica de operação da internet, os limites da liberdade de expressão foram confrontados à luz dos diplomas normativos, da jurisprudência e de doutrinas. Avaliou-se a possibilidade de indisponibilização de conteúdo, com base nos requisitos estabelecidos no Marco Civil da Internet, inclusive por meio de medida liminar. Ao final, foi dedicado um capítulo às formas de responsabilização civil dos provedores e a sua proteção jurídica. Concluiu-se: que os limites da liberdade de expressão deverão ser determinados caso a caso, por meio do posicionamento subjetivo do magistrado, que irá sopesar, no caso concreto, interesses, valores e princípios colidentes; que a remoção compulsória de conteúdo da internet dependerá da ilicitude do conteúdo, reconhecida pelo juiz, de decisão judicial e de indicação de URL, salvo quando o conteúdo reputado ilícito violar a intimidade sexual de outrem; e que na maioria dos casos a baixa eficácia das sentenças que determinam a retirada de conteúdo ocorre pela lentidão do Judiciário e do modus operandi da internet. No que tange à retirada por meio de liminar, o trabalho concluiu que não é em qualquer caso que ela será cabível, sob o risco de configurar censura prévia. Já quanto à responsabilização dos provedores, a regra geral é a de que a responsabilidade é subjetiva, exceto quando eles contiverem controle prévio do conteúdo postado por seus usuários.
\end{abstract}

Palavras-chave: Responsabilização de provedor. Remoção de conteúdo. Liberdade de expressão. Internet. Tutela liminar.

\section{THE DEBATE ON THE LAWFUL AND UNLAWFUL INTERNET: FREEDOM OF EXPRESSION AND REMOVAL OF CONTENT}

\begin{abstract}
The present work sought an analysis of freedom of expression on the Internet, based on survey of the techniques used by magistrates to resolve conflicts in which it is required to remove content from the internet, in addition to examining the effectiveness of judicial decisions and the accountability of ombudsmen. Considering the technical structure of internet operation, the limits of freedom of expression have been confronted in accordance of normative acts, jurisprudence and doctrines. Was evaluated the possibility unavailability of content, on the basis of the requirements established in the Civil Internet Framework, including by way of an injunction. At the end, a chapter was devoted to the forms of civil accountability of ombudsmen and their legal protection. It was concluded: that the
\end{abstract}

\footnotetext{
${ }^{1}$ Graduando em Direito pela Universidade Federal de Uberlândia. Foi Pesquisador do Grupo de Estudos de Direito Digital pela Universidade Federal de Uberlândia 2018/02. Atua como Estagiário na $3^{\text {a }}$ Promotoria de Justiça do Consumidor em Uberlândia. Coautor do livro coletivo: Estudos Essenciais de Direito Digital, editora LAEC - 2019. E-mail: samuel.nnunes@outlook.com.

${ }^{2}$ Especialista em Direito Processual Civil pela Faculdade de Direito Damásio de Jesus (FDDJ). Bacharel em Direito pelo Centro Universitário do Triângulo (UNITRI). Autor de obras e artigos dedicados ao estudo do Direito. Advogado. E-mail: fredericomirandac@gmail.com.
}

Rev. do Cejur: Prestação Jurisdicional, Florianópolis v.7 n.1, p.96-124, Janeiro-Dezembro. 2019. 
limits of freedom of expression should be determined on a case-by-case, through the subjective positioning of the magistrate, that will consider, in the concrete case, interests, values and principles conflicting; that the compulsory removal of internet content will depend on the illegality of the content, recognized by the judge, of judicial decision and of indication of URL, unless the content deemed unlawful violates the sexual intimacy of another person; and that in most cases the low efficacy of sentences that determine the removal of content occurs by the slowness of the Judiciary and the modus operandi of the internet. In respect to the removel by way of injunction, the work concluded that it is not in any case that it will be applicable, at the risk of setting up prior censorship. As for whether accountability of the ombudspersons, the general rule is that responsibility is subjective, except when they contain prior control of content posted by their users.

Keywords: Accountability of ombudsman. Removal of content. Freedom of expression. Internet. Protection -

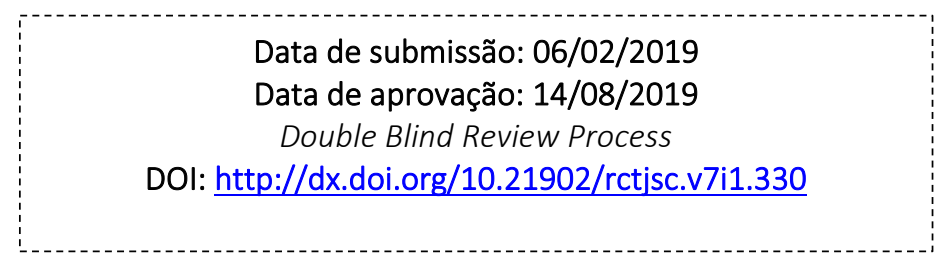

\section{INTRODUÇÃO}

Não é novidade que a sociedade, ao mesmo tempo em que influencia o desenvolvimento da tecnologia, também por ela é influenciada. "A revolução tecnológica ocorrida nos meios de comunicação deu origem a uma nova era denominada como 'Sociedade da Informação"” (BARRETO et. al., 2018, p.144). E nessa sociedade da informação, em que se materializa a necessidade de estar sempre conectado ao "outro", as novas redes de telecomunicações tiveram papel transformador e de grande relevância e repercussão na maneira pela qual as interações sociais se coadunam na contemporaneidade.

Essas transformações sociais causadas pela revolução nos meios de comunicação também trouxeram consigo o aumento significativo de demandas ao Judiciário brasileiro, sobretudo no que diz respeito à solicitação de retirada de conteúdo da internet, influenciada por disposições do Marco Civil da Internet. Entretanto, esses confrontos nem sempre implicam soluções pacíficas do ponto de vista hermenêutico e, por vezes, levam a algumas limitações aos direitos fundamentais, especialmente no que se refere à liberdade de expressão, como nos casos de pedido de remoção de conteúdo da web.

A internet se tornou a ágora, a praça pública do homem moderno, ao mesmo tempo em que, para muitos, se tornou a própria voz do cidadão comum. Sendo assim, inevitavelmente 
haverá conflitos entre as pessoas que expressam posicionamentos diferentes, e esse fenômeno tende a se intensificar à medida que mais pessoas aderirem a essa nova ferramenta de comunicação. "O acesso à informação, a capacidade de exercer o direito à liberdade de expressão e a participação que a internet proporciona a todos os setores da sociedade é essencial para uma sociedade verdadeiramente democrática” (ARTICLE 19, 2017, p. 11).

Malgrado o Marco Civil da Internet - elaborado em consonância com a Declaração Universal dos Direitos Humanos e com a Constituição Federal de 1988 - tenha expressamente reconhecido a internet como elemento essencial ao exercício da cidadania, por meio da positivação da liberdade de expressão como seu fundamento e princípio norteador, juntamente assegurou limites a esse princípio, como é o caso da remoção de conteúdo on-line reputado como ilícito, mediante ordem judicial (art. 19, caput) ou extrajudicial, nos casos de violação à intimidade sexual (art. 21, caput).

Entretanto, diante da atual polarização política brasileira, em que as redes sociais são palco de debates calorosos, e da rápida transmissão das notícias por meio da internet, o Judiciário frequentemente se vê diante do difícil dilema do lícito e do ilícito nos casos concretos envolvendo o direito fundamental à liberdade de expressão e outros princípios colidentes, v.g., direito à imagem, também protegido pela Constituição.

Nesse contexto, o presente artigo irá se ater aos litígios sobre remoção de conteúdo da World Wide Web, especificamente no que tange à técnica usada pelos magistrados para solução desses conflitos, à responsabilização civil dos provedores e aos requisitos, à luz do Marco Civil da Internet.

Contudo, o presente artigo não pretende esgotar o tema; antes disso, o que se objetiva é um estudo jurisprudencial e doutrinário sobre as questões suscitadas, e como elas interferem, positiva ou negativamente, na liberdade de expressão.

\section{LIBERDADE DE EXPRESSÃO, UM DIREITO FUNDAMENTAL}

A liberdade de expressão sempre foi e, hodiernamente, ainda é a principal ferramenta de engajamento não só político, mas também democrático. Em seu íntimo, guarda a essência de países não autoritários, consubstanciada na livre expressão de ideias e pensamentos, sem qualquer tipo de censura, uma exigência para o exercício de outros direitos intrínsecos ao cidadão

Rev. do Cejur: Prestação Jurisdicional, Florianópolis v.7 n.1, p.96-124, Janeiro-Dezembro. 2019. 
A Declaração Universal dos Direitos Humanos, que tem por escopo o delineamento dos direitos básicos inerentes à pessoa humana, independentemente de nacionalidade ou qualquer outro fator discriminatório, predita em seu artigo XIX que: "todo ser humano tem direito à liberdade de opinião e expressão; este direito inclui a liberdade de, sem interferência, ter opiniões e de procurar, receber e transmitir informações e ideias por quaisquer meios e independentemente de fronteiras".

Conforme ensina Gilmar Mendes, "a liberdade de expressão é um dos mais relevantes e preciosos direitos fundamentais, correspondendo a uma das mais antigas reivindicações dos homens de todos os tempos" (2018, p. 389). As normas de direitos fundamentais, segundo uma visão dogmática, podem ser definidas como aquelas que, uma vez positivadas na Constituição, são expressamente integradas ao rol de disposições consagradas no capítulo atinente aos direitos fundamentais (ALEXY, 2006). Na Constituição Federal, esse direito fundamental está elencado no texto normativo do art. $5^{\circ}$, inciso IV, in verbis: "é livre a manifestação de pensamento, sendo vedado o anonimato"3.

No entanto, esse direito ganhou contornos diferentes desde a popularização da internet, instrumento que maximizou o exercício da liberdade de expressão. Sobre o papel da internet na constituição da sociedade da informação, predita o ilustríssimo preceptor Benkler que:

[...] em rede temos que cada indivíduo é livre para observar, responder, questionar e debater, não apenas em princípio, mas na capacidade atual. Enfim, não precisamos limitar-nos a apenas ler, ouvir e assistir, podemos participar do debate. Como mídia alternativa, a internet e a economia da informação em rede permitem-nos uma participação maior, não encontrada na mídia de massa. (apud BRANCO et. al., 2009, p. 19).

\footnotetext{
${ }^{3}$ Sobre o tema Gilmar Mendes explica: "a Constituição cogita da liberdade de expressão de modo direto no art. $5^{\circ}$, IV, ao dizer 'livre a manifestação do pensamento, sendo vedado o anonimato', bem como no inciso XIV do mesmo artigo, em que 'é assegurado a todos o acesso à informação e resguardado o sigilo da fonte, quando necessário ao exercício profissional', e também no art. 220, quando dispõe que 'a manifestação do pensamento, a criação, a expressão e a informação, sob qualquer forma, processo ou veículo não sofrerão qualquer restrição, observado o disposto nesta Constituição'. Acrescenta, nos $\S \S 1^{\circ}$ e $2^{\circ}$ do mesmo artigo, que 'nenhuma lei conterá dispositivo que possa constituir embaraço à plena liberdade de informação jornalística em qualquer veículo de comunicação social, observado o disposto no art. $5^{\circ}, \mathrm{IV}, \mathrm{V}, \mathrm{X}, \mathrm{XIII}$ e XIV', e que 'é vedada toda e qualquer censura de natureza política, ideológica e artística’. Incluem-se na liberdade de expressão faculdades diversas, como a de comunicação de pensamentos, de ideias, de informações, de críticas, que podem assumir modalidade não verbal (comportamental, musical, por imagem etc.). $\mathrm{O}$ grau de proteção que cada uma dessas formas de se exprimir recebe costuma variar, não obstante todas terem amparo na Lei Maior" (MENDES, 2018, p. 388-289).
}

Rev. do Cejur: Prestação Jurisdicional, Florianópolis v.7 n.1, p.96-124, Janeiro-Dezembro. 2019. 
O Marco Civil da Internet, por sua vez, define a liberdade de expressão como seu fundamento (artigo $2^{\circ}$, caput). Nesse sentido, Victor Hugo Pereira Gonçalves ensina:

O Marco Civil parte do pressuposto principiológico de que a liberdade de expressão é a função conceitual do meio de comunicação internet. A internet é o canal por onde as pessoas e cidadãos se expressam e se envolvem em conteúdos e práticas. (GONÇALVES, 2017, p. 10).

E complementa dizendo que:

Para tanto, o Marco Civil deve garantir e disciplinar o uso dessa nova ágora. A liberdade de expressão é o fundamento, o princípio, mas os incisos deste art. $2^{\circ}$ são os limites e problematizam o a situação do cidadão "total". Bobbio já alertou que pior que não ter democracia é o excesso dela. Qualquer princípio por natureza não é absoluto e tem os seus limites. Contudo, a liberdade de expressão, como teoria e prática nas redes de informação e comunicação, possui infinitas limitações que não são enfrentadas pelo Marco Civil. (GONÇALVES, 2017, p. 11).

Sendo um direito fundamental, seus limites devem ser estudados cautelosamente, ainda mais se considerada a remoção de conteúdo da internet, pois seus efeitos não afetam somente aquele que se expressa, mas toda uma coletividade que tem direito à informação e à participação política. O grande problema, quando se trabalha com a remoção de conteúdo da internet, está consubstanciado na definição do que seria "liberdade de expressão" ou, mais precisamente, seu âmbito de proteção ${ }^{4}$. Entretanto, para definição dos limites desse direito fundamental, faz-se necessária uma breve diferenciação entre princípios e regras.

\section{PRINCÍPIOS E REGRAS}

O sistema normativo brasileiro, no que tange às suas disposições, pode ser classificado basicamente em normas que constituem princípios e normas que configuram regras.

\footnotetext{
${ }^{4}$ Nesse sentido, Victor Hugo Pereira Gonçalves explica: "em termos práticos, a eleição da liberdade de expressão, em detrimento de outros princípios, esconde discursos e situações que obstam o acesso do cidadão 'total'. A imagem da Ágora, atrelada ao Marco Civil, obnubila as práticas que a diferem substancialmente daquelas vividas pelos gregos. Os cidadãos gregos, mais especificamente os homens livres, acessavam a qualquer momento a Ágora sem restrições. Contudo, com a internet, vê-se que a maioria dos cidadãos são dela excluídos. Os excluídos digitais não podem exercer o seu direito à liberdade de expressão nem de pensamento. Por outro lado, existem os incluído que não podem exercer a sua liberdade de expressão porque não têm cultura, educação ou, simplesmente, são obstados por vigilantismo estatal, privado ou judicial" (GONÇALVES, 2017, p.12).
}

Rev. do Cejur: Prestação Jurisdicional, Florianópolis v.7 n.1, p.96-124, Janeiro-Dezembro. 2019. 
Malgrado não seja correto afirmar que as normas possam ser classificadas exclusivamente em regras ou princípios, posto que as classificações podem variar de acordo com a teoria estrutural que se adota, essa divisão se mostra a mais adequada ao estudo dos direitos fundamentais e ao objetivo deste trabalho. Antes dessa análise, é de estrita importância ementar a diferença entre texto normativo e norma.

Normas são, na visão de Humberto Ávila (2005, p. 22), “os sentidos construídos a partir da interpretação sistemática dos textos normativos" . Isso implica dizer que os dispositivos normativos não possuem conteúdo definido a priori, dependendo de atividade interpretativa $a$ posteriori e levando em conta a ordem jurídica como um todo, para que seja subtraída a norma, ou seja, o seu significado, em consonância com as demais disposições. Porém, essa interpretação possui alguns limites, posto que, nos textos normativos "há traços de significado mínimos incorporados ao uso ordinário ou técnico da linguagem" (ÁVILA, p. 24, 2005). Neste caminho, seria congruente lembrar os ensinamentos de Hans Kelsen (1999), o qual, ao tratar da interpretação das leis e, por óbvio, dos textos normativos, esclareceu que a aplicação do direito, que se dá por via interpretativa, é resultado da subtração, dentro da moldura prefixada na lei, de um dos significados desta, pelo operador do direito, tendo todos esses significados igual valor.

Portanto, o produto da atividade interpretativa de um dispositivo legal é uma norma, podendo ela ser uma regra ou um princípio. Regras são, na concepção de Dowrkin, normas aplicáveis pelo sistema do "tudo-ou-nada"; assim, observada a concretização da hipótese de incidência descrita no texto normativo, a consequência jurídica é aplicada automaticamente (ALVES, 2013). Por não possuírem dimensão de peso, elas se limitam a estipular obrigações, permissões e proibições por meio da descrição de uma conduta hipotética, garantindo dessa forma direitos definitivos, salvo quando houver cláusula de exceção (FRANCO, 2013).

Os princípios, de modo diverso das regras, são mandados de otimização, devendo ser realizados na medida do possível, observadas as condições fáticas e jurídicas do caso concreto (ALEXY, 2006). Portanto, os princípios possuem dimensões de peso, podendo ser realizados de modo gradual, diferentemente das regras, que são aplicadas no todo, ou não são aplicadas. À vista disso, não é incorreto afirmar que os princípios pressupõem um “estado ideal de coisas" a ser atingido, o que incorre em concluir que os princípios não são normas absolutas. 
Ademais, os princípios possuem várias funções no ordenamento jurídico, o que os difere substancialmente das regras. Pode-se resumi-las basicamente em três: função integrativa, interpretativa e valorativa do ordenamento jurídico. Especificamente no que se refere à função valorativa, frise-se, os princípios exortam valores e, sendo valor um conceito histórico, estes tendem a mudar de acordo com a evolução das relações sociais e históricas, o que exige uma frequente análise do seu âmbito de proteção.

Sendo abrangentes e amplas, as normas principiológicas frequentemente estão sujeitas a conflitos com outros princípios, o que exige dos operadores do Direito uma análise detalhada do caso concreto, a fim de que se pondere qual dos colidentes deve prevalecer. Neste caso, deverá ser atribuído aos princípios em conflito pesos de maior ou menor grau. Diferentemente das regras, os princípios não garantem direitos definitivos e possuem baixo grau de densidade semântica, o que exige, in concreto, uma atividade hermenêutica densa por parte do operador do Direito, a fim de que este lhes subtraia seu significado. Por isso, é importante analisar se uma norma constitui princípio ou regra, quando se trata de direitos fundamentais.

\subsection{Liberdade de Expressão: Princípio ou Regra?}

Como dito anteriormente, uma norma (gênero) pode ser enquadrada como princípio ou regra (espécies), e essa diferenciação implicará efeitos diretos sobre o âmbito de aplicação e eficácia da norma utilizada. Assim, para saber se a liberdade de expressão no Brasil é considerada um princípio ou uma regra, é essencial analisar os textos normativos e doutrinários sobre o assunto.

Em um primeiro momento é importante esclarecer que o direito de liberdade de expressão engloba diferentes direitos, como ensina Fernanda Carolina Tôrres: "mais do que um direito, a liberdade de expressão pode ser entendida como um conjunto de direitos relacionados às liberdades de comunicação" (TÔRRES, 2013, 62).

No mesmo sentido, ensina Rui Barbosa (1978, p. 100): “de todas as liberdades, a do pensamento é a maior e a mais alta. Dela decorrem todas as demais. Sem ela todas as demais deixam mutiladas a personalidade humana, asfixiada a sociedade, entregue à corrupção o governo do Estado".

Rev. do Cejur: Prestação Jurisdicional, Florianópolis v.7 n.1, p.96-124, Janeiro-Dezembro. 2019. 
Nesse contexto, é importante destacar o pensamento de Luís Gustavo Grandinetti Castanho de Carvalho, citado por Thalyta dos Santos, in verbis:

A liberdade de expressão, que se trata tanto do direito de emitir opiniões e informações quanto ao direito de recebê-las, tem sua origem na liberdade da palavra, que, consequentemente, engloba a liberdade de pensamento, visto que nada haveria de efetivo no pensamento sem a liberdade de sua emissão. (SANTOS, 2016, p. 106 apud CARVALO, 1999, p.20).

Assim, é patente que a liberdade de expressão é um princípio geral norteador da Constituição, da qual derivam várias outras liberdades individuais ${ }^{5}$. Prevista em diversos artigos da atual Carta Magna brasileira, no artigo 5, incisos IV, IX, bem como nos artigos 220 e 224, não restam dúvidas sobre sua natureza fundamental ao ser humano. Entendimento contrário seria funesto, já que o âmbito de proteção desse princípio é definido em consonância com outros valores que são a ele contraposto, variando caso a caso.

Tal a importância desse direito para o engajamento político e democrático do cidadão, que mereceu também tratamento no Marco Civil da Internet, influenciando todo o seu conteúdo e, de igual modo, sua interpretação. Por isso, o legislador, considerando o papel da internet na democracia, não economizou nas palavras, recitando a liberdade de expressão como seu fundamento (art. $2^{\circ}$, caput) e princípio norteador do MCI (art. $3^{\circ}$, inciso I).

Seu importante destaque no MCI, explica Marcacini (2016), se deve ao fato de que, além de ser um princípio inerente à inteligência e à personalidade humana, é também uma ferramenta à qual a sociedade recorre para controlar o exercício do poder político e os atos dos agentes públicos. Não só como controle, a liberdade de expressão é parte intrínseca de uma sociedade livre e democrática, razão pela qual, discorre Alexandre de Morais, "não pode sofrer nenhum tipo de limitação prévia" (2017, p. 256).

Nesse aspecto, após essa breve explicação e levando em conta as considerações do tópico anterior, é possível concluir que a liberdade de expressão se enquadra na definição de princípio, pelo fato de ser um "mandamento de otimização" e pela possibilidade da colisão desse direito com outros, observadas as condições fáticas e jurídicas do caso concreto.

\footnotetext{
${ }^{5}$ Segundo Gilmar Mendes: "a liberdade de expressão é, então, enaltecida como instrumento para o funcionamento e preservação do sistema democrático (o pluralismo de opiniões é vital para a formação de vontade livre)" (MENDES, 2028, p. 390).
}

Rev. do Cejur: Prestação Jurisdicional, Florianópolis v.7 n.1, p.96-124, Janeiro-Dezembro. 2019. 
Por isso, devido aos pontos apresentados, ao seu alto grau de generalidade e baixa densidade semântica, bem como à sua configuração como direito fundamental, a definição dos limites da liberdade de expressão deverá ser analisada caso a caso, posto não ser um direito absoluto, e sim um direito relativo. Passa-se agora para uma análise das teorias e de suas implicações na extensão desse direito.

\section{TEORIAS PARA DEFINIÇÃo DO ÂMBITO DE PROTEÇÃO DA LIBERDADE DE EXPRESSÃO}

Consoante ao explicado em tópico anterior, a liberdade de expressão constitui um princípio, positivado na Declaração Universal dos Direitos Humanos, na Constituição Federal e também no Marco Civil da Internet. Neste capítulo será analisado o âmbito de aplicação da liberdade de expressão conforme a doutrina e a jurisprudência.

A norma e, por conseguinte, seu espaço de aplicação são determinados a partir de uma atividade de interpretação. Virgílio Afonso da Silva (2017), ao analisar a eficácia dos direitos fundamentais, ensina que há basicamente duas formas de se analisar o âmbito de proteção de uma norma. Segundo as teorias que defendem um suporte fático restrito dos direitos fundamentais, o operador do Direito opta por excluir, a priori, algumas condutas, estados ou posições jurídicas do âmbito de proteção de uma norma. Desta forma, negam a colisão entre princípios e a restrição aos direitos fundamentais, uma vez que determinam prima facie quais condutas são ou não protegidas por uma norma de direito fundamental (teoria interna). Assim, verbi gratia, expressões ofensivas poderiam não fazer parte da proteção da liberdade de expressão ao magistrado adepto dessa teoria.

De encontro com essa corrente, Virgílio elenca as teorias que defendem um suporte fático amplo dos direitos fundamentais (teorias externas); assim, não há uma exclusão a priori de quais condutas podem ou não ser abarcadas pelo âmbito de proteção de um direito fundamental. O que ocorre é a extensão do âmbito de proteção de um direito fundamental a todo e qualquer ato que, uma vez analisado isoladamente, possa ser enquadrado na norma (SILVA, 2017). Desta forma, usando o mesmo exemplo citado anteriormente, ao invés de se declarar que ofensas não são protegidas pelo direito à liberdade de expressão, o magistrado opta por incluí-las no âmbito de proteção desse direito. Com isso, há frequentemente colisão entre os princípios, que deverá ser 
solucionada por meio da atribuição de pesos, em menor ou maior grau, aos casos concretos, pelo confronto entre os mais variados bens jurídicos tutelados pelo ordenamento.

Como será visto em tópico posterior, não é válido fazer juízo de valor entre teoria correta e incorreta, sendo ambas adotadas amplamente pelo Judiciário para resolução das lides envolvendo a liberdade de expressão na internet. Porém, importa-nos para o presente trabalho frisar as características de cada uma delas, tendo em vista que, a depender da corrente adotada pelo magistrado, sua argumentação é substancialmente transformada e, consigo, também o âmbito de proteção da liberdade de expressão. A propósito, assevera Marcacini (2016, p. 82):

[...] os contornos que definem as fronteiras entre um direito à liberdade de expressão e a prática de comportamento ilícito resultam essencialmente de um posicionamento político, em que se atribua àquela maior ou menor abrangência, sempre em detrimento de interesses de outros sujeitos que possam ser atingidos pela mais liberdade de divulgação da mensagem.

Seguindo essa ideia, preleciona Norberto Bobbio (1992) que os direitos fundamentais, em sua maioria constituídos na forma de princípios, são, antes de tudo, direitos relativos, na medida em que o seu âmbito de proteção variará caso a caso, através de uma decisão subjetiva, pelo operador do direito, em que pese a definição do limites desse direito e do outro com ele colidente in concreto. Consequentemente os direitos fundamentais, em tese, com especial destaque para o caso dos princípios, não garantem direitos definitivos a priori, sendo sua proteção definida a posteriori pelo magistrado, observado o núcleo essencial mínimo desses princípios.

\section{O DEBATE DO LÍCITO E DO ILÍCITO NA WEB}

Estudadas algumas formas básicas de definição do conteúdo de um direito fundamental, faz-se mister, sob o prisma jurisprudencial e doutrinário, estudar qual a amplitude da liberdade de expressão na internet. O Marco Civil exige, como requisito para remoção de conteúdo da internet, que o conteúdo objeto de remoção seja ilícito, cabendo ao Judiciário determinar o que deve ou não ser enquadrado como ilícito. 
Contudo, o juízo de valor sobre determinado conteúdo postado na internet, especificamente no que diz respeito à liberdade de expressão, dependerá da estratégia hermenêutica adotada pelo juiz ao caso concreto, conforme descrito no tópico anterior. $\mathrm{O}$ Supremo Tribunal Federal, em se tratando de casos difíceis envolvendo direitos fundamentais, nomeadamente no que tange à liberdade de expressão, tem sido assente em adotar a teoria externa, trazendo ao debate jurídico a necessidade de, nos casos concretos, balancear os princípios colidentes, conforme pode ser destacado em acórdão recente, cujo Ministro Relator Luiz Fux, proferiu:

Apesar de não se tratar de direito absoluto, a liberdade de expressão possui alcance amplo, abrangendo todo tipo de opinião, convicção, comentário ou avaliação sobre qualquer tema ou sobre qualquer indivíduo, envolvendo tema de interesse público ou não, não cabendo ao Estado a realização do crivo de quais dessas manifestações devem ser tidas ou não como permitidas, sob pena de caracterização de censura (STF, 2018b).

A técnica do balanceamento, ensina Dimitri, se consubstancia na ideia de uma "ponderação de valores ou bens jurídicos, estudando o respectivo peso e devendo prevalecer aquela que, na situação concreta, apresenta maior relevância e importância" (DIMITRI apud AGRA, 2018, p. 186). Em outras palavras, Daniel Sarmento [entre 2006 e 2015, p. 55] explica que a ponderação corresponde "ao que os juízes e intérpretes fazem de fato nestes casos difíceis pesam e contrapõem interesses, valores, argumentos".

Referindo-se à liberdade de expressão, em meio à técnica da ponderação, orquestrou o Ministro Barroso em julgamento em que se discutia remoção de conteúdo da internet:

A CRFB/1988 incorporou um sistema de proteção reforçado das liberdades de expressão, informação e imprensa, reconhecendo uma prioridade prima facie destas liberdades públicas na colisão com outros interesses juridicamente tutelados, inclusive com os direitos da personalidade. Assim, embora não haja hierarquia entre direitos fundamentais, tais liberdades possuem uma posição preferencial, o que significa dizer que seu afastamento é excepcional, e o ônus argumentativo é de quem sustenta o direito oposto. (STF, 2018c).

A respeito desse tema, e levando em conta a multiplicidade de condutas que a liberdade de expressão abrange, dissertou o Ministro Alexandre de Morais:

O direito fundamental à liberdade de expressão não se direciona somente a proteger as opiniões supostamente verdadeiras, admiráveis ou convencionais, 
mas também aquelas que são duvidosas, exageradas, condenáveis, satíricas, humorísticas, bem como as não compartilhadas pelas maiorias. Ressalte-se que, mesmo as declarações errôneas, estão sob a guarda dessa garantia constitucional (MORAIS et al, 2018, p. 69).

Seguindo essa linha de pensamento, ensina o professor Sylvio Motta (2018) que, mutatis mutandis, a liberdade de expressão abrange toda e qualquer manifestação expressa oralmente ou por escrito, desenho, mímica, pintura, fotografia, independentemente de sua veiculação, seja ela por jornal, livro, revista, rádio, televisão, internet, entre outros. Porém, por mais que seja um dos princípios mais importantes para a democracia, ele não deve prevalecer sobre a ética, a verdade e a honestidade, razão pela qual não deve servir a interesses ocultos de disseminar mentiras e boatos que visem prejudicar a honra e a reputação de pessoas ou instituições, com agravante para os casos que envolver abusos na internet, dada suas peculiaridades de funcionamento (MORAIS et al, 2018, p. 157).

\section{ARQUITETURA DA INTERNET E REMOÇÃO DE CONTEÚDO ILÍCITO}

O âmbito de proteção de um direito fundamental, como visto anteriormente, pode ser definido de várias formas e, mesmo que seu exercício exceda os limites, não há espaço para censura prévia. Doutro modo, quase tão importante quanto saber como um conteúdo é interpretado como ilícito, é estudar a eficácia das sentenças judiciais que determinam a remoção de um conteúdo da internet. Sem embargo, para melhor compreensão desse tópico, é estritamente necessário entender o funcionamento da rede mundial de computadores, especialmente se considerada a orla prejudicial que um conteúdo ilícito pode gerar a depender da gravidade e da repercussão que tiver na sociedade interconectada.

"A internet é agora parte da vida cotidiana de milhões de pessoas ao redor do mundo e tornou-se assim uma exigência básica para o exercício significativo do direito da liberdade de expressão" (ARTICLE 19, 2012, p. 6). Portanto, é de estrita importância entender as peculiaridades que permeiam a estrutura de funcionamento da internet, não devendo estas serem ignoradas pelos magistrados quando da resolução de conflitos, sob pena de um conteúdo vagar eternamente numa infinidade de "bits" espalhados pelo mundo inteiro, ou mesmo de violar direitos de inúmeros usuários interconectados. 
O Marco Civil da Internet define, em seu artigo $5^{\circ}$, inciso I, internet como sendo "o sistema constituído do conjunto de protocolos lógicos, estruturado em escala mundial para uso público e irrestrito, com a finalidade de possibilitar a comunicação de dados entre terminais por meio de diferentes redes". De origem militar e fundada nos Estados Unidos em findos anos 60, a internet é, antes de tudo, uma rede mundial de computadores interligados entre si.

No Brasil, a implantação da internet só foi possível em 1995, quando o governo federal estendeu seu acesso ao setor privado, o que possibilitou a exploração comercial da rede mundial (MORAIS et al., 2012). Essa rede é composta por uma infinidade de "nós" (peers), cada qual podendo comunicar-se aos outros pontos da rede, tendo acesso a qualquer conteúdo disponibilizado por outros "nós". Isso se deve essencialmente à principal característica da internet, que é sua interoperabilidade, ou seja, trata-se de uma rede descentralizada que permite a comunicação entre os computadores conectados à rede, por variados caminhos (nós). Em breves palavras, a internet é uma verdadeira "cidade", na qual os "nós" funcionam como "ruas" que permitem a conexão e interconexão entre eles.

Para que isso seja possível, os computadores precisam estar interligados por canais, que nada mais são do que emissores de sinais que permitirão que uma das peers se conecte com a outra; por exemplo: cabos coaxiais, fibra ótica e radiodifusão. Ademais, é impreterível que esses computadores possuam a mesma linguagem, a fim de que seja possível a comunicação e a troca de informação. Contemporaneamente, essa comunicação é realizada pelo protocolo lógico TCP/IP versão 4.

Cada um dos pontos da rede recebe um número IP - Internet Protocol -, que facilitará a identificação dos terminais. O IP é o "endereço" do computador; o número que viabilizará que uma informação seja enviada ou recebida por ele. Essas informações são divididas em vários pacotes de dados, cada qual contendo o endereço do destinatário da informação. A partir de então, esses pacotes seguem rumo ao destinatário, passando por vários "nós", até chegarem ao endereço para o qual foram programados, onde serão reunidos novamente (MARCACINI, 2016).

Neste sentido, leciona LONGHI (2019, p. 128): "a internet surgiu como um meio de comunicação difuso, cujo princípio básico é o de que não importa por onde as informações trafeguem, mas sim de onde partem e para onde vão”. Isso graças a sua descentralização, permitida por meio das "peers". 
Portanto, a título exemplificativo, quando uma mensagem é postada em uma rede social de forma pública, cada um dos "nós" da rede pode, desde que conectado à internet, ter acesso e compartilhá-la com vários outros "nós" e, ao mesmo tempo, ser receptor de várias outras informações. Descrevendo os impactos que a internet pode ocasionar na propagação de informações, predita Átila: "[...] há uma intensa e volumosa transmissão de dados e informações, em velocidade cada vez maior, de forma que qualquer dado, foto, vídeo ou conteúdo pode percorrer todo o planeta em questão de segundos, ultrapassando facilmente as barreiras temporais e/ou territoriais" (LIMA, 2019, p. 45).

À vista disso, dado o princípio da interoperabilidade que rege o funcionamento da internet, muitas decisões judiciais que determinam a remoção de conteúdo nem sempre são eficientes. O primeiro fator determinante para essa casuística é a falta de conhecimento técnico dos magistrados e dos operadores do Direito, que, desconsiderando o modus operandi da internet, culminam por adotar medidas que em muitos casos são vazias ou impossíveis de se realizarem tecnicamente.

Outro ponto que contribui para a ineficácia de grande parte dessas sentenças é a lentidão do Poder Judiciário em relação às exigências de respostas rápidas para amenizar os danos a determinada pessoa, dadas as peculiaridades de operabilidade da internet, precipuamente no que se refere à velocidade e reciprocidade da troca de informações, característica principal do que convém hoje denominar "sociedade da informação".

\section{REQUISITOS PARA REMOÇÃO DO CONTEÚDO DA INTERNET}

O Marco Civil, em seu artigo 19 e seguintes, versa sobre a remoção compulsória de conteúdo da internet e, nesses dispositivos, é possível encontrar requisitos para que essa remoção seja considerada legal. Todavia, tem-se também a possibilidade de isso ocorrer diretamente pelos provedores; isso porque a maioria deles oferta seus serviços por meio de contratos e, dentro 
destes, podem existir regras autorizadoras para a remoção de conteúdos que estejam em desacordo com seus termos de uso $^{6}$.

Para iniciar o debate, é de estrita importância acentuar que o Marco Civil da Internet, quando alude à remoção de conteúdo, cria para esta uma regra geral e, concomitantemente, uma regra específica, de modo que não há que se falar em uma antinomia.

A regra geral está consubstanciada no disposto no art. 19, caput, enquanto a regra específica se encontra no art. 21. Ao analisar a regra geral, é possível subtrair três critérios que devem estar presentes para que seja possível a remoção de um conteúdo da internet. O primeiro deles estipula que só podem ser removidos compulsoriamente da internet os conteúdos ilícitos, ou seja, aqueles que extrapolam manifestamente o exercício da liberdade de expressão.

O segundo trata da necessidade de decisão judicial que determine a remoção do conteúdo ilícito da internet. Na prática, o Marco Civil transfere ao Judiciário a legitimidade para ditar o que deve ou não ser removido da internet, caso o provedor não o faça após solicitação da suposta vítima. Consequentemente, caberá ao Judiciário o julgamento do que seria lícito ou ilícito na internet. Tal análise, conforme visto em capítulos anteriores, levará em conta, na maioria dos casos, a técnica da ponderação.

Por fim, o último critério é que haja a determinação clara e específica do instrumento reputado como ilícito, que, de acordo com sólido entendimento da jurisprudência brasileira, só se verifica com a inserção do URL (Uniform Resource Locator). Esse verificador, em breves palavras, opera como um tipo de "sinônimo" do IP, ou seja, nada mais é do que o endereço web do conteúdo.

Nesse ponto, os estudiosos Roth e Nunes (2019, p. 147), ao analisarem o texto normativo do $\S 1^{\circ}$ do art. 19 , descrevem que a norma subtraída dele não possui conteúdo normativo claro, uma vez que "[...] nela, o legislador optou por se limitar a criar uma norma geral para a validade da ordem judicial, deixando a cargo do judiciário o papel de determinar qual seria o método para a identificação clara e específica do conteúdo normativo”.

Já no que tange à regra específica, a remoção do conteúdo dependerá da constatação, in concreto, da violação da intimidade sexual de determinada pessoa. Nesses casos, poderá ser

\footnotetext{
${ }^{6}$ Entretanto, deve se atentar ao fato de que, na outra ponta da relação contratual, existe o sujeito autor do conteúdo removido, que poderá pleitear indenização - responsabilidade civil contratual - caso se comprove que tal conteúdo era lícito.
}

Rev. do Cejur: Prestação Jurisdicional, Florianópolis v.7 n.1, p.96-124, Janeiro-Dezembro. 2019. 
requerida até por notificação extrajudicial ao provedor, conhecida como regra do notice and takedown (notificar e retirar), sob pena de responsabilização objetiva pelo conteúdo postado. À primeira vista, pode parecer um dispositivo totalmente inconsistente, dada a disposição do art. 19 aqui estudada. Porém, essa crítica não deve sobrelevar-se, uma vez que, conforme explicado no início do tópico, trata-se de uma regra específica, tendo o legislador julgado de estrita importância uma proteção maior ao direito à intimidade, em se tratando de violações à intimidade sexual.

Segundo Victor Hugo Pereira Gonçalves (2018), o art. 21 carece de taxatividade e se mostra deveras discricionário, uma vez que estabelece como único critério para a determinação da retirada do conteúdo pornográfico a falta de consentimento, não explicando de que forma este deve ser emanado e a quem, se ao usuário que fez o upload, ao provedor, ou a ambos.

Esse consentimento poderá ser dos próprios participantes ou dos representantes legais deles. Assim, descrevem Damásio de Jesus e José Antônio Milagre (2014, p. 70):

Em casos de conteúdos gerados por terceiros envolvendo divulgação sem autorização de seus participantes, de imagens, vídeos ou de outros materiais contendo cenas de nudez ou de atos sexuais de caráter privado, o próprio participante ou seu representante legal poderão, diretamente e sem a necessidade de ordem judicial, notificar o provedor de aplicações que hospeda o conteúdo.

Tão logo receba a notificação do participante ou de seu representante legal, deverá o provedor agir de modo a tornar indisponível o conteúdo cuja publicação não foi acompanhada do consentimento dos integrantes. No entanto, isso não impede que a indisponibilização seja também ordenada por determinação judicial, caso o provedor se recuse a fazê-lo, ou mesmo se a vítima preferir esse meio.

Em suma, ao examinar o pedido de remoção de conteúdo, o primeiro passo é verificar se se trata de violação à intimidade sexual, tais como as relacionadas ao revenge porn e à invasão de dispositivo por hackers, com a obtenção e publicação de fotos íntimas de determinada pessoa. Em não sendo dessa ordem, aplicar-se-á a regra geral - art. 19 do Marco Civil da Internet. 


\section{POSSIBILIDADE DA RETIRADA DE CONTEÚdO DA INTERNET POR MEIO DE LIMINAR}

Em capítulo anterior, atinente às eficácias das decisões judiciais, a problemática apresentada referiu-se justamente à baixa efetividade das decisões judiciais, devido à morosidade do processo judicial na resolução de lides envolvendo a remoção de conteúdo da internet em contraposição à velocidade de propagação das informações na rede mundial de computadores e sua interoperabilidade. Uma das alternativas, difundida por diversos tribunais, para aumentar a eficácia das sentenças tem sido a concessão de liminares para indisponibilização temporária do conteúdo, uma vez verificados os pressupostos necessários para a concessão das tutelas de urgência, definidos no próprio Código de Processo Civil. Contudo, o tema reserva impasses, os quais serão analisados neste tópico.

De antemão, ressalte-se que a maior dificuldade ao estudo desse tema relaciona-se aos conteúdos não enquadrados na regra específica do art. 21 do MCI, quais sejam, aqueles que não ferem a intimidade sexual de outrem.

Em se tratando de pedidos de remoção de conteúdo que, excedendo os limites da liberdade de expressão, violem a honra, a reputação ou outros direitos da personalidade, o debate ganha outros contornos, que devem ser analisados cuidadosamente, com risco de violações sistematizadas aos direitos fundamentais dos vários cibernautas. Inicialmente, é necessário ressaltar que o MCI, no art. $19, \S 3^{\circ}$, permite que as decisões relacionadas à responsabilização de provedor e indisponibilização de conteúdo sejam proferidas pelos juizados especiais civis, e, por não especificar qual tipo de decisão judicial poderá determinar que o provedor tire do ar o conteúdo que exceda os limites da liberdade de expressão, não há impedimentos para que o provimento jurisdicional seja feito por medida liminar. Contudo, deve-se analisar esse dispositivo detalhadamente, à luz dos princípios constitucionais.

Nos processos judiciais, a Constituição assegura a todos a garantia de isonomia, da ampla defesa e do contraditório ${ }^{7}$. Porém, em alguns casos, esse contraditório poderá ser

\footnotetext{
${ }^{7}$ Ensina Gilmar Mendes: "o direito ao contraditório e à ampla defesa, com os recursos a ela inerentes, tem âmbito de proteção de caráter normativo, o que, de um lado, impõe ao legislador o dever de conferir densidade normativa adequada a essa garantia e, de outro, permite-lhe alguma liberdade de conformação. Ao regular o direito ao contraditório e à ampla defesa não pode o legislador desequiparar os interesses e as partes em conflito, Rev. do Cejur: Prestação Jurisdicional, Florianópolis v.7 n.1, p.96-124, Janeiro-Dezembro. 2019.
} 
postergado, autorizando o juiz a conceder a medida liminar solicitada na petição inicial, em caráter provisório, sem ouvir o réu antecipadamente. O contraditório não é suprimido, mas sim atrasado pelo risco iminente e irreparável ao objeto da lide ou ao provimento jurisdicional, não possuindo a decisão caráter definitivo. De fato, não resta questionamentos sobre a constitucionalidade das medidas antecipadas e cautelares; porém, em se tratando de remoção de conteúdo da internet, seja por juizado comum, seja por juizado especial, o uso de tal instrumento deve considerar os efeitos da sentença sobre centenas de milhares de usuários na internet.

Conforme apresentado ao longo do trabalho, se os contornos que delineiam os limites da liberdade de expressão são feitos por meio do contraditório, em que pese a dialética das partes em juízo que servirá de embasamento para que o magistrado, no exercício da ius jurisdictionis, sopese os princípios colidentes, de fato, fica difícil advogar no sentido de ser cabível a concessão de liminares que determinem a remoção de conteúdo da internet deliberadamente, sob o risco de caracterizar censura prévia. Contudo, a concessão de liminar não necessariamente acarretará censura prévia, pois a medida apenas irá funcionar como um instrumento de proteção aos direitos personalíssimos de outrem, uma vez constatado manifestamente o abuso da liberdade de expressão em contraposição com outros direitos (fumus boni iuris) e o risco de prejuízo irreversível ao resultado útil do processo (periculum in mora), dado o princípio da interoperabilidade da internet e a repercussão do conteúdo tido como ilícito. Nessa direção, observando os aspectos técnicos da internet, leciona Souza e Lemos (2016, p. 105):

É verdade que a velocidade da Internet supera em muito a velocidade de um processo judicial, razão pela qual é sempre importante destacar que, convencido o magistrado de que existem boas razões para concluir que a permanência do conteúdo no ar agravará sensivelmente a situação da vítima, deve o mesmo acolher uma medida liminar para a remoção do conteúdo.

Entretanto, o STF tem rechaçado expressamente a remoção de conteúdo da internet por tutela provisória, independentemente de se verificarem abusos ao exercício da liberdade de expressão. Em julgado recente, o STF declarou, dentre outras coisas, que “[...] a medida própria para a reparação do eventual abuso da liberdade de expressão é o direito de resposta e não a

estabelecendo os meios necessários para que se atinja o equilíbrio entre estas, garantindo, assim, tratamento paritário entre as partes no processo" (MENDES, 2018, p. 725).

Rev. do Cejur: Prestação Jurisdicional, Florianópolis v.7 n.1, p.96-124, Janeiro-Dezembro. 2019. 
supressão liminar de texto jornalístico, antes mesmo de qualquer apreciação mais detida quanto ao seu conteúdo e potencial lesivo", sendo esse direito de resposta constituído pela remoção do conteúdo, responsabilização civil e eventualmente a penal, após sentença condenatória transitada em julgado.

Nessa ocasião, analisando a ação o Ministro Alexandre de Morais, em seu voto, proferiu:

[...] A liberdade de expressão desfruta de uma posição preferencial no Estado democrático brasileiro, por ser uma pré-condição para o exercício esclarecido dos demais direitos e liberdades. 4. Eventual uso abusivo da liberdade de expressão deve ser reparado, preferencialmente, por meio de retificação, direito de resposta ou indenização. Ao determinar a retirada de matéria jornalística de sítio eletrônico de meio de comunicação, a decisão reclamada violou essa orientação [...] o exercício de jurisdição cautelar por magistrados e Tribunais não pode converter-se em prática judicial inibitória, muito menos censória, da liberdade constitucional de expressão e de comunicação, sob pena de o poder geral de cautela atribuído ao Judiciário qualificar-se, anomalamente, como um novo nome de uma inaceitável censura estatal em nosso País". (STF, 2018a).

Ainda sobre a concessão de liminar para retirada de conteúdo da internet, em outro julgamento, o Ministro Celso de Melo decidiu que:

[...] Toda e qualquer decisão que determine recolhimento ou impedimento de publicação de material jornalístico constitui censura. No caso, a confirmação pelo E. TJ/PR da liminar que determinou a retirada do vídeo produzido pelos Reclamantes é, sem qualquer dúvida, exercício de censura, sendo absolutamente desnecessária a leitura ou o debate do conteúdo contido no material jornalístico. (STF, 2019).

Discursando sobre o direito à resposta, garantido constitucionalmente no art. $5^{\circ}$, incisos V e X, e os princípios norteadores desse direito, Sarlet descreveu:

Outro princípio que informa o regime jurídico do direito de resposta é o da imediaticidade, pois, para preservar a sua utilidade, a divulgação da resposta deve ser realizada com a maior brevidade possível, o que, considerando a evolução tecnológica e a utilização, por exemplo, da internet para o exercício da liberdade de expressão, demanda uma capacidade de reação e adaptação dificilmente compatível com os limites de um processo judicial, por mais ágil que este seja (2017, p. 634).

Além da discrepância entre as velocidades do processo judicial e da circulação das informações, o que per si já pode ocasionar prejuízos irreparáveis ao direito de resposta, outro 
problema é a grande facilidade de anonimato que a rede mundial de computadores proporciona aos seus usuários, o que pode ser conseguido verbi gratia por meio do uso de "máscaras" de IP pelos terminais, ou mesmo pelo uso de proxies. Convencido o magistrado, in concreto, com base em provas suficientes que levem à conclusão de anonimato, de abuso sobrepujante da liberdade de expressão e, consigo, de prejuízos irreversíveis à vítima do ilícito caso aquele conteúdo não seja indisponibilizado, não há por que não conceder a liminar. Dessa forma, a fim de que não se agrave a situação danosa, em obediência aos valores constitucionais da dignidade da pessoa humana, imagem, honra e intimidade consubstanciados na lex Mater, evita-se o risco de serem irreversíveis os danos causados à vítima do ilícito, dadas as especificidades da rede mundial de computadores.

Em suma, percebe-se que há, por parte do Supremo Tribunal Federal, certa resistência à concessão de liminar para remoção de conteúdo da internet, independentemente de se constatar que houve abusos à liberdade de expressão. Todavia, ao se pronunciar nesse entendimento é evidente que o STF não exclui a possibilidade total de retirada de conteúdo por liminar, como é o caso da regra do art. 21 do MCI, que determina a retirada de conteúdo publicado na rede mundial de computadores, mesmo que por notificação extrajudicial, de conteúdo que exponha "sem autorização de seus participantes, de imagens, de vídeos ou de outros materiais contendo cenas de nudez ou de atos sexuais de caráter privativo”, e sempre que houver indícios exorbitante do ilícito e possíveis prejuízos irreparáveis, levando-se em conta uma interpretação lógico-sistemática do ordenamento.

\section{RESPONSABILIDADE CIVIL DOS PROVEDORES}

O funcionamento da internet, e por consequência da maximização da liberdade de expressão no ciberespaço, é permitido graças aos provedores, que garantem a inserção de conteúdos que possam ser acessíveis pelas "peers" conectadas à rede mundial de computadores. Esses provedores podem ser classificados em provedores de conexão à internet, aqueles responsáveis por ensejar que os terminais possam se conectar à World Wide Web; e provedores de aplicação da internet, que são aqueles responsáveis por assegurar um conjunto de funcionalidades que podem ser acessadas por meio de um terminal conectado à internet. 
Os provedores de aplicação (PAI), também denominados de provedores de serviços, são aqueles que "permitem o acesso a programas, aplicativos e arquivos como e-mail, hospedagem, bate papo, música etc.” (GNET, 2016, p. 26). Durante muito tempo se debateu qual o tipo de responsabilidade que esses provedores teriam, frente a conteúdo ilícito postado por terceiros. Assim, este capítulo abordará a responsabilidade dos provedores de aplicação pelos danos causados por esses conteúdos, à luz da Constituição, do Marco Civil da Internet e da jurisprudência ${ }^{8}$, pois, a depender, se objetiva ou subjetiva, a responsabilidade dos provedores impactará diretamente suas políticas e, por conseguinte, os limites da liberdade de expressão na internet.

A responsabilidade civil compreende, no direito das obrigações, um dos elementos da obrigação, traduzido no dever de responder, com seu patrimônio, ao adimplemento de determinada obrigação. Entretanto, segundo ensinamentos de Tartuce (2017), a responsabilidade civil também pode ser estudada em seu viés extracontratual, como um ônus atribuído ao autor de um ato ilícito ou que, por abuso do exercício de um direito, cause prejuízos a outrem. Essa responsabilidade civil dependerá da corrente adotada ao caso concreto e das disposições legais.

No caso dos provedores de aplicação, a responsabilização civil pode ser tanto subjetiva quanto objetiva, a depender do seu modo de funcionamento, sendo esta última exceção à regra. Sobre a responsabilização objetiva, durante tempos, firmaram-se preponderantemente duas teses para defender sua aplicação, a saber: a da teoria do risco e a do defeito de serviço, embasado no art. 14 do CDC. Cristiano Colombo e Eugênio Faccini Neto explicam que os adeptos da responsabilidade objetiva:

[...] defendiam que os provedores poderiam utilizar programas-filtro, quando, antecipadamente, através de um prévio controle, preveniriam o cometimento de ilícitos. Para tanto, poderiam efetuar ou um controle amplo e prévio ou, mais realisticamente, um controle por amostragem, ou, ainda, um controle somente $a$ posteriori, removendo os conteúdos tidos como ilícitos ou inconvenientes. (2018, p. 217).

\footnotetext{
${ }^{8}$ Antes, faz-se necessário acentuar que não restam dúvidas sobre a impossibilidade de responsabilização civil dos provedores de acesso à internet, uma vez que a mera viabilização, pelo provedor de acesso, de conexão à rede mundial pelo terminal "não parece ser a causa direta e imediata do dano sofrido pela eventual vítima, mas sim o comportamento concretamente desempenhado pelo usuário que gerou o conteúdo ilícito" (SOUZA; LEMOS, 2016, p. 98). Em consonância com essa ideia, o Marco Civil da Internet, em seu artigo 18, elencou que "o provedor de conexão à internet não será responsabilizado civilmente por danos decorrentes de conteúdo gerado por terceiros". Isso não se aplica aos provedores de aplicação, como veremos a seguir.
}

Rev. do Cejur: Prestação Jurisdicional, Florianópolis v.7 n.1, p.96-124, Janeiro-Dezembro. 2019. 
A teoria do risco, positivada no art. 927, parágrafo único, traz a responsabilização civil, independentemente de culpa, quando a atividade desenvolvida por um autor implicar riscos aos direitos de outrem. Destarte, sob essa tese, se defendia que a atividade dos provedores de aplicação era de risco e, portanto, eles deveriam ser responsabilizados.

No entanto, buscando a máxima efetivação da liberdade de expressão, o Superior Tribunal de Justiça assentou sólido entendimento no sentido de não ser possível a aplicação dessa teoria aos danos causados por terceiros; vide trecho de uma das decisões recentes sobre o tema:

EMENTA: INDENIZAÇÃO - DANOS MATERIAIS E MORAIS DISPONIBILIZAÇÃO NA INTERNET DE MATERIAIS DE AUTORIA DO REQUERENTE E COMERCIALIZADOS POR ELE RESPONSABILIDADE CIVIL OBJETIVA - TEORIA DO RISCO - DEVER DE INDENIZAR QUANTUM INDENIZATÓRIO - FIXAÇÃO. [...] Como é sabido, a responsabilidade objetiva decorre da lei ou quando a atividade a que se relaciona o ato implicar por sua natureza riscos para os direitos de outrem. No caso vertente, a hospedagem de dados de terceiros por meio de sites na Internet jamais poderia ser considerada atividade de risco, pois não há qualquer controle ou ingerência por meio do sito hospedeiro sobre o conteúdo inserido por terceiros. (STJ, 2019).

A outra tese que ganhou certa aceitação no mundo jurídico estava instaurada na ideia de defeito de serviço prestado (art. 14 do CDC) por parte do provedor, constatado pela falta de controle prévio de conteúdo inserido por terceiros, como medida de espreita preventiva. Porém, malgrado o Superior Tribunal de Justiça tenha sólido entendimento de que os serviços oferecidos pelos provedores de aplicação estão sujeitos ao CDC, por auferirem lucro indiretamente, o Tribunal compreendeu não ser possível determinar, compulsoriamente, que os provedores introduzam uma fiscalização prévia do conteúdo ${ }^{9}$, uma vez que o dever de vigilância não faz parte da essência do serviço prestado. Assim, Carlos Roberto Gonçalves, citando parte do voto da Ministra Nancy Andrighi em julgado em que se discutia essa tese, descreveu:

[...] o provedor deve assegurar o sigilo, a segurança e a inviolabilidade dos dados cadastrais de seus usuários, além de garantir o pleno funcionamento das páginas que hospeda. Entretanto, não pode ser obrigado a exercer um monitoramento prévio das informações veiculadas por terceiros, pois não se trata

\footnotetext{
${ }^{9}$ Esse entendimento está sob nova análise pelo STJ em relação aos provedores de comércio eletrônico, aqueles cujo desenvolvimento da atividade econômica se destina primordialmente à venda de produtos e serviços [REsp 1.654.221. $3^{\mathrm{a}}$ turma STJ].
}

Rev. do Cejur: Prestação Jurisdicional, Florianópolis v.7 n.1, p.96-124, Janeiro-Dezembro. 2019. 
de atividade intrínseca ao serviço por ele prestado, [...], razão pela qual a ausência dessa fiscalização não pode ser considerada falha do serviço. (2017, p. $115)$.

Posteriormente, confirmando o entendimento da jurisprudência, o Marco Civil da Internet, no art. 19, caput, estabeleceu positivamente, com o intuito de maximizar a liberdade de expressão e a livre difusão de ideias, a responsabilidade civil subjetiva dos provedores, in omittendo, de modo subsidiário, apenas quando houver descumprimento de decisão judicial que determine a indisponibilização do ilícito na internet, desobrigando o provedor a encetar filtro prévio de conteúdo.

Fazendo uma interpretação do art. 19, consoante os princípios constitucionais, elencaram Maria Celeste e Marilene Araújo (2018, p. 160):

A Constituição brasileira primou pelo princípio da liberdade e posterior responsabilização, o que denota a aproximação com o princípio que orienta as liberdades aqui referidas no direito francês (Artigo 11 da Declaração dos Direitos do Homem e do Cidadão, 1789). Isto quer dizer, primeiramente, que se garante a liberdade de comunicação e depois se responsabilizam os excessos.

Ainda sobre o embate da responsabilização dos provedores, predita Damásio de Jesus e José Antônio Milagre (2014, p. 67) que “o provedor de aplicação só será responsabilizado por conteúdo gerado por terceiros se, e somente se, após ordem judicial, não tomar as medidas para tornar indisponível o referido conteúdo". Também sobre o assunto elucidam Gabriela Roth e Samuel Nunes (2019, p. 143) que:

Esse entendimento tem sua originalidade fundada na tentativa de impedir que os provedores de aplicação (PAIs) estabeleçam uma censura prévia de conteúdo, segundo critérios subjetivos, pois isto configuraria um grande retrocesso à própria democracia e à Lex Mater.

Porém, demonstra-se importante pontuar que a responsabilidade subjetiva não cabe indiscriminadamente a todos os provedores de aplicação, mas apenas àqueles que não possuem filtro prévio de conteúdo. Assim, caso o provedor realize controle prévio de conteúdo, como nos casos dos provedores jornalísticos, que possuem controle editorial das notícias, subsiste o dever de vigilância, respondendo esse provedor solidariamente com o autor do dano a terceiro. 


\section{CONCLUSÃo}

A título conclusivo, destaca-se que, ao longo dessa pesquisa, buscou-se elucidar, notadamente à luz do Marco Civil da Internet (MCI), das normas fundamentais constitucionais, da doutrina e da jurisprudência, o embate jusfilosófico do princípio da liberdade de expressão no ciberespaço, em colisão com outros direitos fundamentais, dada a essencialidade da internet para o exercício pleno da cidadania.

Ao longo deste estudo, ficou evidente que, na Constituição, a liberdade de expressão é uma norma geral, pertencente à espécie de princípios fundamentais e que, como qualquer outra norma jurídica ou princípio, essa liberdade não é absoluta, podendo e devendo ser limitada por outros princípios, necessitando para tanto da utilização do sistema de ponderação dos valores, interesses, argumentos e princípios colidentes. Foi constatado que esse direito, e por conseguinte sua proteção, será resultado de uma atividade subjetiva do magistrado, tendo seu conteúdo definido, caso a caso, em contraste com outros direitos fundamentais de igual valor.

Na pesquisa, foi debatida também a possibilidade de retirada de conteúdo da web por medida liminar, e se evidenciou que nada impede que a decisão liminar, desde que atendidos todos os requisitos legais, possa vir a retirar o conteúdo considerado ilícito, mesmo que temporariamente, considerando-se os aspectos técnicos da internet e outros valores constitucionais contrapostos à liberdade de expressão, a fim de que reste garantida a eficácia das decisões judiciais e o efetivo direito de resposta. Contudo, nesse aspecto, é importante destacar que, com exceção da regra do artigo 21 do MCI (regra específica), a Suprema Corte Brasileira vem decidindo pela impossibilidade da concessão de liminares; porém, sempre que restar comprovado o abuso manifesto da liberdade de expressão, a repercussão do conteúdo e os riscos de se perpetuarem na internet, deve o magistrado conceder a liminar.

Denota-se a prevalência do entendimento de que tem força cogente a norma contida na regra específica, ou seja, da remoção imediata de conteúdo relativo à sexualidade de pessoa que não tenha consentido com a divulgação deste, inclusive por simples notificação ao provedor, que poderá ser responsabilizado, juntamente com a pessoa que postou o conteúdo não autorizado, se notificado, mesmo que extrajudicialmente, e não agir de forma imediata para tornar indisponível o material ilícito.

Rev. do Cejur: Prestação Jurisdicional, Florianópolis v.7 n.1, p.96-124, Janeiro-Dezembro. 2019. 
Ademais, foi rememorada a maximização da liberdade de expressão, que engloba tantas outras formas de liberdade, bem como a possibilidade de responsabilização apenas subjetiva do provedor, pela inteligência do caput do artigo 19 do MCI, que de forma cristalina promove a proteção de tal liberdade e a difusão de ideias no âmbito da rede mundial de computadores.

Foram trazidos ao debate os entendimentos de diversos doutrinadores e a jurisprudência do Supremo Tribunal Federal, realçando-se o papel de ambos os fronts doutrinário e jurisprudencial - para a solução de tais controvérsias, bem como a indubitável importância de os operadores do Direito de modo geral (magistrados, promotores, advogados) conhecerem, mesmo que basicamente, a arquitetura da internet, para que assim possam viabilizar uma eficácia maior das decisões sobre o assunto.

Por fim, pôde ser constatado que a responsabilização civil do provedor, via de regra, deverá ser subjetiva, a fim de que se maximize o direito à liberdade de expressão, desobrigando o provedor de instalar filtros de conteúdo. Dessa Maneira, evita-se uma "ditadura da informação" por parte do setor privado, ou um "estado de vigilância total".

\section{REFERÊNCIAS}

AGRA, Walber de Moura. Curso de direito constitucional. 9. ed. Belo Horizonte: Forum, 2018.

AGUIAR, Roger Silva. Responsabilidade civil objetiva: do risco à solidariedade. São Paulo: Atlas, 2007.

ALEXY, Robert. Teoria de los derechos fundamentales. Madri: Centro de Estuddios Politicos y Constitucionales, 2001.

ALVES, Graziella Ferreira. Levando os direitos a sério - Dworking. In: BORGES, Alexandre Wallmont et al. Clássicos de direito constitucional. Curitiba: Clássica. 2013.

ALEXY, Robert. Teoria dos direitos fundamentais. São Paulo: Malheiros, 2006.

ARTICLE 19. Conectando: liberdade de expressão, empresas de telecomunicações e provedores de internet. São Paulo: Article 19, 2017.

ÀVILA, Humberto. Teoria dos princípios. 4 ed. São Paulo: Malheiros, 2005. 
BARBOSA, Rui. República: teoria e prática: textos doutrinários sobre direitos humanos e políticos na primeira constituição republicana. Brasília: Câmara dos Deputados, 1978.

BARRETO, Irineu Francisco Junior et al. Marco civil da internet e o direito a privacidade na sociedade da informação. In: Direito, estado e sociedade. p. 114, N. 52, 2018.

BRANCO, Claudia Castelo et al. Olhares da rede. São Paulo: Momento Editora, 2009.

BOBBIO, Norberto. A era dos direitos. 11. ed. Rio de Janeiro: Campus, 1992.

BONAVIDES, Paulo. Curso de direito constitucional. 10. ed. São Paulo: Malheiros, 2000.

BRASIL. Constituição da República Federativa do Brasil. Brasília: Senado Federal, 1988. Disponível em: http://www.planalto.gov.br/ccivil_03/constituicao/constituicao.htm. Acesso em: 15 jul. 2019.

COLOMBO, Cristiano; NETO, Eugênio Facchini. Ciberespaço e conteúdo ofensivo gerado por terceiros: a proteção dos direitos de personalidade e a responsabilização civil dos provedores de aplicação, à luz da jurisprudência do Superior Tribunal de Justiça. In: UNICEB. Direito e Mundo Digital. Vol. 7. $\mathrm{N}^{\mathrm{o}}$ 3. 2017. Disponível em: https://www.publicacoesacademicas.uniceub.br/RBPP/issue/archive. Acesso em: 4 jul. 2019.

CANOTILHO, J.J. Gomes. Direito Constitucional. 6. ed. Coimbra: Livraria Almedina, 1995.

COTS, Márcio; OLIVEIRA, Ricardo. Lei geral de proteção de dados pessoais: comentada. São Paulo: RT, 2018.

DWORKIN, Ronald. Levando os direitos a sério. Trad. Nelson Boeira. 2. ed. São Paulo: Martins Fontes, 2007.

FRANCO, Marcelo Rosa. O sistema normativo - Robert Alexy. In: BORGES, Alexandre Wallmont et al. Clássicos de Direito Constitucional. Curitiba: Clássica. 2013.

GNET; Iris. Curso de Introdução ao direito de internet. Belo Horizonte: UFMG, 2017. Disponível em: http://irisbh.com.br/wp-content/uploads/2017/07/Curso-deIntrodu\%C3\%A7\%C3\%A3o-ao-Direito-de-Internet-GNet.pdf. Acesso em: 1 jul. 2019.

GONÇALVES, Carlos Roberto. Responsabilidade civil. 12. ed. São Paulo: Saraiva, 2017.

GONÇALVES, Victor Hugo Pereira. Marco civil da internet: comentado. 1. ed. São Paulo: Atlas, 2017.

JESUS, Damásio; MILAGRE, José Antônio. Marco civil da internet comentários à Lei n. 12.965/14. São Paulo: Saraiva, 2014. 
KELSEN, Hans. O Estado como integração. Trad. Plínio Fernandes Toledo. São Paulo: Martins Fontes, 2003.

KELSEN, Hans. Teoria pura do direito. trad. João Batista Machado. São Paulo: Martins Fontes, 1999.

LONGHI, João Victor Rozatti. Marco civil da internet no Brasil: breves considerações sobre seus fundamentos, princípios e análise crítica do regime de responsabilidade dos provedores. In: MARTINS, Guilherme Magalhães; LONGUI, João Victor Rozatti. Direito digital: direito privado e internet. 2. ed. Induiatuva: Foco, 2019.

LIMA, Átila Pereira. O direito ao esquecimento na era da sociedade da informação. In: LONGUI, João Victor Rozatti; JÚNIOR, José Luiz de Moura Faleiros. Estudos essenciais de direito digital. Uberlândia: Laecc, 2019.

MARCACINI, Augusto. Aspectos fundamentais do marco civil da internet. São Paulo: Le livros, 2016.

MELlO, Celso Antônio Bandeira de. Conteúdo jurídico do princípio da igualdade. 3. ed. São Paulo: Malheiros, 1995.

MENDES, Gilmar Ferreira. Curso de direito constitucional. 13. ed. São Paulo: Saraiva, 2018.

MORAIS, Alexandre de. Direito Constitucional. 33. ed. São Paulo: Atlas. 2017.

MORAIS, Alexandre de. et al., Constituição Federal Comentada. Rio de Janeiro: Forense. 2018.

MORAIS, Carlos Tadeu Queiroz de. et al. Conceitos sobre internet e web. Porto Alegre: UFRGS, 2012.

MOTTA, Sylvio. Direito constitucional. 27. ed. São Paulo: Forense, 2018.

NEVES, Daniel Amorim Assumpção. Manual de direito processual civil. 9. ed. Salvador: JusPodivm, 2017.

ROTH, Gabriela; NUNES, Samuel. A responsabilidade civil dos provedores por danos causados a terceiros: um estudo doutrinário e jurisprudencial do artigo 19 do marco civil da internet. In: LONGUI, João Victor Rozatti; FALEIROS JÚNIOR, José Luiz de Moura. Estudos essenciais de direito digital. Uberlândia: Laecc, 2019.

SANTOS, Maria Celeste Cordeiro Leite dos; ARAUJO, Marllene. O tempo e o espaço: fragmentos do marco civil da internet: paradigmas de proteção da dignidade humana. In: UNICEB. Direito e mundo digital. Vol. 7, $\mathrm{N}^{\mathrm{o}}$ 3, 2017. Disponível em: https://www.publicacoesacademicas.uniceub.br/RBPP/issue/archive. Acesso em: 4 jul. 2019. 
SANTOS, Thalyta. A liberdade de expressão na república federativa do Brasil: aspectos destacados acerca da ratificação do Brasil da convenção americana sobre direitos humanos. Revista Direito UFMS. Campo Grande - MS, v. 2, n.1, 2016, p. 101-119. Disponível em: http://seer.ufms.br/index.php/revdir/article/view/2276. Acesso em: 17 jul. 2019.

SARMENTO, Daniel. Liberdade de expressão e o problema do "hate speech". [entre 2006 e 2015]. Disponível em: http://www.dsarmento.adv.br/content/3-publicacoes/18-a-liberdade-deexpressao-e-o-problema-do-hate-speech/a-liberdade-de-expressao-e-o-problema-do-hate-speechdaniel-sarmento.pdf. Acesso em: 15 jun. 2019.

SARLET, Ingo Wolfang et al. Curso de direito constitucional. 6. ed. São Paulo: Saraiva.

SOUZA, Carlos Affonso; LEMOS, Ronaldo. Marco civil da internet: construção e aplicação. Juiz de Fora: Editar, 2016.

SILVA, José Afonso. Aplicabilidade da norma constitucional. 4. ed. São Paulo: Malheiros, 2000.

SILVA, Virgílio Afonso. Direitos fundamentais: conteúdo essencial, restrições e eficácia. 2. ed. São Paulo: Malheiros.

STJ. REsp 1280317. Relator: Ministro Antonio Carlos Ferreira. DJe: 09/04/2019. Disponível em:https://scon.stj.jus.br/SCON/decisoes/toc.jsp?processo=1.280.317\&ementa=DANOS+MATE $\underline{\text { RIAIS+E+MORAIS+TEORIA+DO+RISCO+INTERNET\&b=DTXT\&thesaurus=JURIDICO\&p }}$ =true. Acesso em: 10 jul. 2019.

STF. Rlc 28747/PR. Relator: Ministro Alexandre de Morais. DJe: 05/06/2018. Brasília: DJe, 2018a. Disponível em: http://redir.stf.jus.br/paginadorpub/paginador.jsp?docTP=TP\&docID=748634834. Acesso em: 25 jun. 2019.

STF. Rlc 30105/PA. Relator: Ministro Luiz Fux. DJe: 15/06/2018. Brasília: DJe, 2018b. Disponível em: http://www.stf.jus.br/portal/jurisprudencia/visualizarEmenta.asp?s1=000290878\&base=baseMon ocraticas. Acesso em: 10 jun. 2019.

STF. Rlc 31117/PR. Relator: Ministro Celso de Mello. DJe: 03/05/2019. Brasília: DJe, 2018. Disponível em: http://www.stf.jus.br/portal/jurisprudencia/visualizarEmenta.asp?s1=000411411\&base=baseMon ocraticas. Acesso em: 11 jul. 2019.

STF. Rlc 31315 TP/SP. Relator: Ministro Roberto Barroso. DJe: 10/08/2018. Brasília: DJe, 2018c. Disponível em: http://www.stf.jus.br/portal/jurisprudencia/visualizarEmenta.asp?s1=000355290\&base=baseMon ocraticas. Acesso em: 1 jul. 2019.

Rev. do Cejur: Prestação Jurisdicional, Florianópolis v.7 n.1, p.96-124, Janeiro-Dezembro. 2019. 
TARTUCE, Flávio. Manual de direito civil. 7. ed. São Paulo: Forense, 2017.

TÔRRES, Fernanda Carolina. O direito fundamental à liberdade de expressão e sua extensão. Revista de informação legislativa. Out/dez. 2013, p. 61-80. 